\title{
Evaluation of Total Factors Productivity of Three Ilam Major Products (Wheat, Corn and Cucumbers)
}

\author{
Dariush Rahmati ${ }^{1} \&$ Bahman Gholami ${ }^{1}$ \\ ${ }^{1}$ Department Agricultural Economics Payame Noor University, Tehran, Iran \\ Correspondence: Dariush Rahmati, Department of Management Payame Noor University, PO Box 19395-3697, \\ Tehran, Iran. E-mail: bahman.manager80@gmail.com
}

Received: June 3, $2015 \quad$ Accepted: June 17, $2015 \quad$ Online Published: October 31, 2015

doi:10.5539/mas.v9n12p70 URL: http://dx.doi.org/10.5539/mas.v9n12p70

\begin{abstract}
The purpose of this study is to evaluate the productivity of total factors Production(water, land and labor) of three Ilam major products which are wheat, corn and cucumber. This study is calculated by conventional methods of measuring productivity and production function of Cobb- Dougles. The results of this study showed that the average productivity cost (during 2000-2009) of lading the ground for irrigated farm is $111.727 \$$ and for dry farm it is $17.468 \$$.the average productivity in this period for lading the labors in irrigated farm of wheat is 2.932 \$and for dry land ,it is 1.237 \$. The Average productivity of the land for cultivation of maize is 1356600 Riyals and for work force is $26.51 \$$. The obtained average productivity of labor and cucumber lands during this period is 1.600 and $208.833 \$$.

Water productivity in the production of Cucumber for Dareshahr and Sarableh cities is respectively 1.112 and 0.437 .Average productivity of water in cucumber productions is 0.774 . The differences of corn productivity of the two cities is almost the same but Mehran and Aivan have the highest and the lowest productivity in Ilam, Mehran has 0.675 and Aivan has 0.274 of productivity. The average productivity is 0.416 . The ratio of the highest and lowest value of the obtained product from each unit of water in Dareshahr is more than $4 / 5$ times. Thus the value of the water product in the cultivation of cucumbers is over $1.729 \$$, while this number for wheat is only $0.367 \$$.
\end{abstract}

Keywords: productivity, products, Ilam Province, wheat, corn and cucumbers

\section{Introduction}

Because of traditional agriculture, the agriculture sector in Iran couldn't use the institutions and factors of production during past years. So in this sector we can increase the national economy with the previous level of production factors (Bagherzadeh \& Komijani, 2011).Today, with the development of technology and science, the identification and control over productive resources and their exploitation is one of the major factors in development, particularly poverty reduction as well as to overcome the current food crisis. As economic prosperity and autonomy of each nation depends on the operation and use of all facilities, capabilities and material and spiritual talent (Ghorbani, 1996). Today the enhancing producing of total factor productivity is the best and the most effective way to achieve economic development with considering scarcity of other traditional production factors (labor, capital and intermediate inputs).(MehrAra\&ahmadzadeh,2009)Increased production is possible in two ways ,one is the using factors of production in the form of technology and the other is to increasing production through using more efficient methods and better technology or increasing the productivity of production factors. As for scarcity production factors there are low possibility to increase production through the use of more productive resources. Therefore, the efforts should be made through the use of inputs and the use of new technologies to improve the performance (Seyyedan, 2010). This is especially about rare institutions such as water crisis which is serious and very important. The Knowledge of economic efficiency of institutions is important for policy. Because the overuse of them will reduce production and increase production costs and national capital will be loss, too. Productivity is a general and overall concept. The purpose of increasing productivity is to improve human life and to create a more prosperous community. Due to the scarcity of resources, efficiency is the most effective way to achieve economic growth (Bagherzade\&Komijany, 2011).Efficiency is utilization of productive resources, labor, capital, equipment and facilities, energy, materials and scientific management, reduce manufacturing costs, to eliminate waste, expanding markets etc, so to improve the quality of life and economic. Improving productivity is always good and it grounds the public welfare, the international competitiveness, 
efficient use of resources, and improve the quality of goods and services. Finally, it causes economic development in community. In order to enhance the contribution of productivity to economic growth by one third at the end of the fifth socio-economic development plan (2011-2015)the productivity of all production factors such as labor, capital, energy, water and soil, Iran National Productivity Institute affiliated to the Department of State is created with the use of existing facilities. The productivity of the country master plan includes standard indicators of operational productivity and efficiency promotion, including the distribution of roles and responsibilities in all areas of social, economic and cultural sectors, both public and private, as the program enters into force for all of the above(Fifth Five Year Plan). Providing food security infrastructures and Promotion of agricultural sector based on sustainable development consideration of seven percent $(7 \%)$ has been attended especially about two products wheat and maize which are compared with the developments of 2009 , As well as improving irrigation efficiency of at least forty percent $(40 \%)$ in the final year of the program through the implementation of infrastructure projects which is included water and soil, equipping and modernization, the development of networks, drainage and new irrigation methods is emphasized by the fifth five-year plan of Islamic Republic. According to the subjects which were told the importance of studying the efficiency of products such as wheat and corn which are one of the most important products in Ilam province and Cucumber is also important in terms of production in the country .The world's economic growth and productivity of the agricultural sector was studied by Gerdin (2002) during the period of 1964 to 1996 . The results of this study showed that capital and labor have had the highest and the lowest assistance to growing the products. The productivity growth in total production during of the course has been $0 / 36$ percent.

\section{Method}

Productivity is the ratio of output to input. In general, most economists have considered two kinds of productivity; marginal and average(Heidari, 1998). Final productivity is the amount of the last unit of input which is added to total output. And average productivity is the amount of output to data unit or, in other words, on average, how much each data unit adds to output. There are many ways to measure productivity. As regards to each measurement method has specific goals so the choice of the appropriate method of measuring is depended to identify analytical purposes, the availability of statistics and necessary information to measure productivity .There are variety of concepts and definitions of productivity and different applications which dependent on the circumstances, there are so different ways of measuring (Shakeri, 2006). There are two ways for calculating the productivity; one is econometric method and the other is non-parametric method. The calculating of the production function efficiency and the cost function is done through econometric method. Productivity in non-parametric method is determined by using of mathematical program or calculating of index. The calculation of efficiency is based on physical and values criteria. In physical mode the production factors are based on the amount of weight, number, length, volume, and product as well as physical measurements(Fatahi,2006).The value productivity calculates the ratio of value-added productivity of farm to value of used inputs.

$$
\mathrm{y}=a_{0} \pi x_{i}^{\alpha n}
$$

\subsection{Final Total Factor Productivity}

Final Total Factor Productivity indicates an increase in production than an increase of one unit in a particular input. In fact, it is the final production. In other words, the productivity index has defined as the ultimate performance of an additional unit, on condition that the amount of other inputs has not been changed.

\subsection{Total Factors Productivity}

TFP determines production changes to a set of factors production changes which have been considered. Early indicator is the value of production to the set of harmonies values of factors used production; however, the three factors of labor, capital, and energy are used in the process of production. Two-step clusters analysis is used to classify cities in terms of the productivity of scarce inputs. The method is as follows: 


$$
T F P E=\frac{Q_{t}}{\alpha_{t}\left(r_{t} K_{t}+w_{t} L_{t}+e_{t} E_{t}\right)} \times 100
$$

First of all, in two-stage approach analysis, the groups are identified and then the average is grouping by Kmethod. The above mentioned method is as follows. In the K- Average method for classification of observations, at first each item is assigned to clusters which have the closest distance with the central observation. Then distance of each observation is calculated from the center of categories and it re-assigns to the nearest group. The distance between two observations is as follows which the matrix of variances and Covariance are samples, this method is preferred for clustering then the others. (Johnson \&Vichren, 2000) .

$$
d(x, y)=\sqrt{(x-y)^{\prime} A(x-y)}
$$

The advantage of this method is that, the observation can be divided without knowing the number of divisible clusters (SPSS Inc., 2002).

\section{Results}

The productivity index is defined as value added per each hectare of land and labor. It should be noted that the above criteria was calculated for water efficiency as physical and value productivity. Among the products in this province 3 major products are studied in the calculation of these indices. Added Value is calculated on the basis of constant prices of 2000.This provides comparisons across years for each product. The period of studding included 2000-2009year.

Statistics related to the cultivation and production of three studied products of Ilam In order to compare the statistics for the area under cultivation and production in tons as well as the kilogram performance of three products in the annals is extracted of Ministry of Agriculture, and it is provided in the tables of 1 to 3 .

Table 1. Shows Statistic and quantity of wheat under cultivation in Ilam province during 2000-2009

\begin{tabular}{lllllllll}
\hline Production(ton) & \multicolumn{3}{c}{} & \multicolumn{3}{c}{ Cultivation(hec) } \\
\cline { 2 - 8 } & $\begin{array}{l}\text { Dry } \\
\text { farming }\end{array}$ & Irrigated & aggregate & $\begin{array}{l}\text { Dry } \\
\text { farming }\end{array}$ & Irrigated & aggregate & $\begin{array}{l}\text { Dry } \\
\text { farming }\end{array}$ & Irrigated \\
$\mathbf{2 0 0 1 - 2 0 0 0}$ & $\mathbf{1 2 6 2}$ & $\mathbf{3 8 2 8}$ & $\mathbf{2 3 8 1 1 9}$ & $\mathbf{1 1 5 2 2 3}$ & 122896 & 123365 & 91265 & 32100 \\
$2001-2002$ & $\mathbf{6 1 8}$ & $\mathbf{3 0 0 5}$ & $\mathbf{1 4 1 3 0 8}$ & $\mathbf{4 4 8 1 6}$ & 96491 & 104544 & 72436 & 32108 \\
$2002-2003$ & $\mathbf{6 4 0}$ & $\mathbf{3 6 5 5}$ & $\mathbf{1 8 7 8 7 5}$ & $\mathbf{5 1 8 8 7}$ & 135987 & 118245 & 81043 & 37202 \\
$2003-2004$ & $\mathbf{1 0 4 5}$ & $\mathbf{3 6 6 2}$ & $\mathbf{2 4 1 6 0 5}$ & $\mathbf{9 9 0 7 3}$ & 142531 & 133676 & 94758 & 38918 \\
$2004-2005$ & $\mathbf{1 1 2 2}$ & $\mathbf{3 8 1 2}$ & $\mathbf{2 6 2 3 6 8}$ & $\mathbf{1 0 7 4 9 8}$ & 154869 & 136349 & 95731 & 40618 \\
$2005-2006$ & $\mathbf{1 2 2 1}$ & $\mathbf{3 6 6 1}$ & $\mathbf{2 9 4 4 2 6}$ & $\mathbf{1 1 9 0 5 7}$ & 175368 & 145367 & 97478 & 47889 \\
$2006-2007$ & $\mathbf{2 9 7}$ & $\mathbf{1 9 4 9}$ & $\mathbf{8 3 7 4 4}$ & $\mathbf{3 8 1 4}$ & 79930 & 53799 & 12802 & 40997 \\
$2007-2008$ & $\mathbf{8 5 6}$ & $\mathbf{3 2 1 9}$ & $\mathbf{1 9 8 5 6 4}$ & $\mathbf{5 7 2 1 4}$ & 141350 & 110700 & 66795 & 43905 \\
$2008-2009$ & $\mathbf{1 0 1 2}$ & $\mathbf{2 8 5 8}$ & $\mathbf{2 4 0 1 1 3}$ & $\mathbf{9 7 3 5 9}$ & 142754 & 146116 & 96167 & 49949 \\
\hline
\end{tabular}

Source: statistics of Ministry of Jahadkeshavarzi.

Table 2. This part shows the statistic of area under cultivation and quantity of corn production in Ilam during 2000-2009

\begin{tabular}{lrrr}
\hline season & Cultivation(hec) & Production(ton) & Proceeds(kg) \\
\hline $\mathbf{2 0 0 1 - 2 0 0 0}$ & $\mathbf{4 4 9 9}$ & $\mathbf{2 5 5 2 4}$ & $\mathbf{5 6 7 3}$ \\
$2001-2002$ & $\mathbf{4 7 3 2}$ & $\mathbf{2 7 3 6 6}$ & $\mathbf{5 7 8 3}$ \\
$2002-2003$ & $\mathbf{4 1 6 2}$ & $\mathbf{2 6 1 9 1}$ & $\mathbf{6 2 9 2}$ \\
$2003-2004$ & $\mathbf{4 0 6 4}$ & $\mathbf{2 3 6 2 2}$ & $\mathbf{5 8 1 2}$ \\
$2004-2005$ & $\mathbf{5 0 1 9}$ & $\mathbf{2 4 3 5 7}$ & $\mathbf{4 8 5 3}$ \\
$2005-2006$ & $\mathbf{4 1 0 7}$ & $\mathbf{2 6 7 9 9}$ & $\mathbf{6 5 2 5}$ \\
$2006-2007$ & $\mathbf{4 5 7 8}$ & $\mathbf{2 7 7 5 3}$ & $\mathbf{6 0 6 2}$ \\
$2007-2008$ & $\mathbf{4 1 9 3}$ & $\mathbf{2 4 8 1 3}$ & $\mathbf{5 9 1 7}$ \\
$2008-2009$ & $\mathbf{8 1 4 7}$ & $\mathbf{6 0 2 6 9}$ & $\mathbf{7 3 9 7}$ \\
\hline
\end{tabular}

Source: statistic of Jahadkeshavarzi Ministry. 
Table 3. This part shows the statistic of area under cultivation and quantity of cucumber production in Ilam during 2000-2009

\begin{tabular}{lrrr}
\hline season & Cultivation(hec) & Production(ton) & Proceeds(kg) \\
\hline $\mathbf{2 0 0 1 - 2 0 0 0}$ & $\mathbf{5 1 2 4}$ & $\mathbf{9 3 9 9 4}$ & $\mathbf{1 8 3 4 3}$ \\
$2001-2002$ & $\mathbf{4 1 8 7}$ & $\mathbf{6 2 7 6 2}$ & $\mathbf{1 4 9 8 9}$ \\
$2002-2003$ & $\mathbf{6 5 7 9}$ & $\mathbf{1 5 2 2 4 4}$ & $\mathbf{2 3 1 4 0}$ \\
$2003-2004$ & $\mathbf{6 6 1 4}$ & $\mathbf{1 5 6 0 5 9}$ & $\mathbf{2 3 5 9 5}$ \\
$2004-2005$ & $\mathbf{6 1 9 5}$ & $\mathbf{1 1 8 3 2 7}$ & $\mathbf{1 9 1 0 0}$ \\
$2005-2006$ & $\mathbf{9 6 3 2}$ & $\mathbf{2 0 1 8 7 4}$ & $\mathbf{2 0 9 5 8}$ \\
$2006-2007$ & $\mathbf{4 4 2 6}$ & $\mathbf{8 3 9 3 8}$ & $\mathbf{1 8 9 6 4}$ \\
$2007-2008$ & $\mathbf{5 5 7 1}$ & $\mathbf{1 2 2 3 4 5}$ & $\mathbf{2 1 9 6 1}$ \\
$2008-2009$ & $\mathbf{5 6 3 5}$ & $\mathbf{1 0 1 0 3 0}$ & $\mathbf{1 7 9 2 9}$ \\
\hline
\end{tabular}

Source: statistic of Jahadkeshavarzi Ministry.

\subsection{The Productivity Factors of Rain-Fed and Dry Wheat Production}

Table (4)The most productive of the wheat crop of Ilam has been presented. Based on the results of all the factors of production during 2000-2009land and labor productivity in dry land farming has been much less than irrigated land. The land and labor which is used in the production of wheat was increasing in 2001-2007,but during the last three years period, they decreased productivity. This reduction of the workforce, compared with land is a little more. However, wheat crop for its importance has been supported during the period under study. During the study, the average productivity of irrigated land 111.727 andit is $17.468 \$$ for dry land farming. The difference in labor input productivity is lower than the input of land in two manufacturing systems.

This means that labor productivity in irrigated and rain fed is 2.932 and for dry land is $1.237 \$$ per worker in a day. It should be noted that during this period the growth rate of productivity factors of production in dry land cultivation is more than rain-fed cultivation. So that the average productivity growth is estimated in dry land farming more than $17 \%$ and in rain-fed 1.8 percent. Similar condition sexist on labor input too. During the period of study, growth of labor productivity was obtained 19.6 and in rain-fed land it was obtained a little more than 9percent.More than the in dry land farming and irrigated slightly more than9percent. Rain-fed wheat cultivation used water and chemical fertilizer more than dry land cultivation and the difference in productivity is related to this condition.

Table(4). Productivity of wheat production factors (100sent- constant prices 2000)

\begin{tabular}{lllll}
\hline \multicolumn{2}{c}{ Irrigated } & \multicolumn{3}{l}{ Dry farming } \\
\hline Season & Labor productivity & Land productivity & Labor productivity & Land productivity \\
$2000-2001$ & 1656 & 78282 & 358 & 6125 \\
$2001-2002$ & 2136 & 105718 & 1124 & 16956 \\
$2002-2003$ & 2307 & 98853 & 320 & 4115 \\
$2003-2004$ & 2129 & 73994 & 570 & 8433 \\
$2004-2005$ & 1603 & 98249 & 1052 & 20068 \\
$2005-2006$ & 4297 & 145526 & 2828 & 34524 \\
$2006-2007$ & 4487 & 143254 & 2501 & 31523 \\
$2007-2008$ & 3543 & 128857 & 1235 & 22489 \\
$2008-2009$ & 4238 & 132818 & 1152 & 12982 \\
Average & 2932.8 & 111727 & 1237 & 17468 \\
\hline
\end{tabular}

Reference: research findings. 


\section{2 productivity of Maize Factors Production}

The changes in the productivity of land and labor which are used in the production of corn can be seen as an oscillation cycle. In this way, at the start of period 2001 in relation to the previous year it decreased productivity and a significant increase occurred in 2003.

In 2005, a severe decrease occurred in productivity. After this year there was an increase cycle during2006-2009. The process followed in the case of both land and labor inputs observed. The average productivity of maize is less than rain-fed wheat. But the average of labor productivity in maize production is more than wheat. In the period of studying the productivity factors of production didn't have observable growth.

Table 5. Productivity of maize factors production (100sent- constant prices 2000)

\begin{tabular}{lrr}
\hline \multicolumn{1}{l}{ Season } & Land productivity & \multicolumn{2}{c}{ Labor productivity } \\
\cline { 2 - 3 } $2000-2001$ & $\mathbf{2 9 5 2}$ & $\mathbf{1 3 5 1 9 7}$ \\
$2001-2002$ & $\mathbf{1 7 5 4}$ & $\mathbf{1 0 2 9 3 8}$ \\
$2002-2003$ & $\mathbf{3 8 9 5}$ & $\mathbf{1 9 6 4 5 7}$ \\
$2003-2004$ & $\mathbf{3 4 2 1}$ & $\mathbf{1 7 2 0 7 5}$ \\
$2004-2005$ & $\mathbf{1 1 2 5}$ & $\mathbf{9 3 6 3 9}$ \\
$2005-2006$ & $\mathbf{2 2 6 5}$ & $\mathbf{1 2 8 5 9 0}$ \\
$2006-2007$ & $\mathbf{2 8 4 2}$ & $\mathbf{1 3 5 1 0 2}$ \\
$2007-2008$ & $\mathbf{2 7 5 1}$ & $\mathbf{1 2 3 4 2 2}$ \\
$2008-2009$ & $\mathbf{2 8 5 6}$ & $\mathbf{1 3 3 5 2 6}$ \\
Average & $\mathbf{2 6 5 1}$ & $\mathbf{1 3 5 6 6 0}$ \\
\hline
\end{tabular}

Reference: research findings.

Table 6. Productivity of cucumber factors production (100sent- constant prices 2000)

\begin{tabular}{|c|c|c|}
\hline Season & $\begin{array}{l}\text { Labor } \\
\text { productivity }\end{array}$ & Land productivity \\
\hline $\begin{array}{l}2000-20 \\
01\end{array}$ & 1200 & 165243 \\
\hline $\begin{array}{l}2001-20 \\
02\end{array}$ & 542 & 90105 \\
\hline $\begin{array}{l}2002-20 \\
03\end{array}$ & 215 & 152897 \\
\hline $\begin{array}{l}2003-20 \\
04\end{array}$ & 1742 & 172489 \\
\hline $\begin{array}{l}2004-20 \\
05\end{array}$ & 985 & 117823 \\
\hline $\begin{array}{l}2005-20 \\
06\end{array}$ & 2132 & 275684 \\
\hline $\begin{array}{l}2006-20 \\
07\end{array}$ & 4256 & 489365 \\
\hline $\begin{array}{l}2007-20 \\
08\end{array}$ & 1547 & 210546 \\
\hline $\begin{array}{l}2008-20 \\
09\end{array}$ & 1785 & 205346 \\
\hline Average & 1600 & 208833 \\
\hline
\end{tabular}

Reference: research findings.

\subsection{Productivity Factors of Cucumber Production}

The cycle of oscillation is observed in changes of productivity in production of cucumber .So the period of 2001-2005 consisted a cycle and the period of 2006-2008 consisted another cycle. In each period an increase and a decrease is observable.

With this difference that in second period oscillation is much more than the first period. 
However, while the oscillation cycle productivity is visible in a small increase can be seen in general process. The second cycle is at a higher level of oscillation than the first cycle. In the total period the land productivity has 6.6 average annual growth and the labor productivity has growth of 8.1 percent. The average productivity of land and labor are respectively 20.883 and $1.600 \$$.

\subsection{Water Productivity}

Table (7)which shows the physical productivity of water is presented for different products among different cities. In other words the figures presented in this table represents the obtained product of each unit $\left(\mathrm{m}^{3}\right)$ of water. The figures consumption and operation of water is shown as an average in the period of 1380-88. The difference between the highest and lowest productivity of wheat is more than 2 times Thus, in Ilam per cubic meter of water a little more than $3.0 \mathrm{~kg}$ wheat is produced, while in Dehloran city it is more than $6.0 \mathrm{~kg}$. After Dehloran city there are Darehshahr and Sarableh which these areas are almost adjacent to each other as well as they are using Seimereh River. In table(7) water productivity can be seen of the cucumber production in Sarableh and Drehshahr.

So the water productivity figures for these cities are $0.437,1.112$ and the average of water productivity in cucumber production is 0.774 . The difference of maize productivity except for Mehran and Eivan which have the highest and the lowest productivity in Ilam which the maize productivity in Mehran is 0.675 and in Eivan it's0.274, the maize productivity are almost near between two cities of Dehloran and Eivan.the average productivity is 0.416 . Water corn productivity have better situation in both cities Dehloran and Mehranthan other cities. In the case of all three products in terms of water efficiency, the northern cities are somewhat less than southern cities in Ilam.

Table 7. This part shows the water productivity which is used in the production of Ilam $\left(\mathrm{kg}-\mathrm{m}^{3}\right)$

\begin{tabular}{lllllll}
\hline $\begin{array}{l}\text { City } \\
\text { Yeled }\end{array}$ & Mehran & Evan & Ilam & Dehloran & Sarablah & Dareshahr \\
\hline Wheat & $0 / 328$ & $0 / 332$ & $0 / 318$ & $0 / 654$ & $0 / 362$ & $0 / 436$ \\
Corn & $0 / 675$ & $0 / 274$ & - & $0 / 371$ & - & $0 / 346$ \\
Cucumber & - & - & - & - & $0 / 437$ & $1 / 112$ \\
\hline
\end{tabular}

Resource: research findings.

Table (8) is also provided water efficiency. The figures of this table show the value of obtained product per unit of water $\left(\mathrm{m}^{3}\right)$. The results presented in this table provide comparison of water productivity in the production of different products in each of the cities. It should be noted that the productivity index was calculated as the value of the product obtained from each unit of water was used in 2005 prices. In addition, the prices of various productsfor the entire province were equatedin2005.In Darehshahr city the highest and lowest value of the product obtained from each unit of water is more than5.4times. Thus the value of the product water in the cultivation of cucumbers is over $1.729 \$$, while the figure for wheat is only $0.367 \$$. The index of cucumbers has much difference with the other two products. Cucumber is the most important product of Darehshahr and it also provides more than 80 precent of productions of cucumber in Ilam. After cucumber corn and wheat are respectively 0.574 and $0.367 \$$.Dehloran with $1.032 \$$ has the highest productivity than other cities and water productivity in Mehran between two products hasn't high differences.

Table 8. It provides the water productivity which is used in Ilam production

\begin{tabular}{lllllll}
\hline $\begin{array}{l}\text { City } \\
\text { Yeled }\end{array}$ & Mehran & Evan & Ilam & Dehloran & Sarablah & Dareshahr \\
\hline Wheat & & & & & & \\
Corn & $790 / 7$ & $644 / 2$ & $578 / 5$ & $1032 / 8$ & $815 / 4$ & $367 / 2$ \\
Cucumber & $704 / 6$ & $805 / 9$ & - & $617 / 2$ & & $574 / 9$ \\
\hline
\end{tabular}

\section{Discussion}

Labor and land productivity in the cultivation of wheat in both kinds of cultivation is high during 2006-2007.In 
the case of corn production in the 2003-2004labor productivity and land productivity had been high.Land and labor productivity cucumbers were the highest in 2007. Water productivity in Darehshahr city has had the highest productivity than the other products and than the other cities too. After cucumber of Darehshahr the corn of Mehran and the wheat of Dehloran have the highest rank of Ilam.

Inputs of water in agriculture are so important that these are as have been faced with the phenomenon of drought .Due to the water crisis in the province increasing of productivity of using water should be as a major goal. According to table 7and 8 So that to do this plan regional planning is a Requirement .The tables of this research point out three products which have the highest and the lowest productivity in using of water and this means the possibility of increasing water productivity. According to the results of these tables in general policy of increasing productive it In addition to considering products the region should be considered.

\section{Acknowledgments}

The index-number approach to studying productivity estimates total factor productivity (TFP), which measures levels and changes in agricultural output relative to changes in an aggregated index of multiple inputs. Today, with the development of technology and science, the identification and control over productive resources and their exploitation is one of the major factors in development, particularly poverty reduction as well as to overcome the current food crisis. As economic prosperity and autonomy of each nation depends on the operation and use of all facilities, capabilities and material and spiritual talent.

\section{References}

Bagherzadeh, A., \& Komijani, A. (2011). Analysis effects and Development of internal and external on productivity factors of production in Iran agricultures. Quarterly of Economic Modeling fourth year, 1, 93-119.

Fatahi, A. (2006). Measuring the productivity of the most important affecting factors in production of madder in Yazd. Research and development, 43, 38-72.

Gerdin, A. (2002). Produvtivity and economic growth in Kenyan agriculture: 1964-1996. AgriculturalEconomics. 27, 7-13.

Ghorbani, M. (1995). The effect of insurance on wheat productivity and production of Mazandaran. The collection of First Conference of Agricultural Economics. Zabul.

Heidari, Kh. (1998).Total factor productivityof wheat inMarkazi province.Quarterly of Economic Agriculture and Development. Seventh year, (28), 137-158.

Junson, R., \& Vichren, D. (2000). Applied multivariate statistical analysis. Translator HosseinaliNirumand, Ferdowsi Publication University of Mashhad.

Mehrara, M., \&Ahmadzadeh, A. (2009). The evaluation of role ofTotal FactorProductivityin growing ofmajor economic sectorsin Iran. theJournalof Commerce, 87, 209-232.

Shakeri, A. (2006). Microeconomics. Theories and Applications. NEI Publication, 446-445.

Syydan, S. M. (2001). Analysis ofproductivityinsugar beetproduction factorsCase studycomparinglarge and smallfarmsin the city ofHamedan.Quarterly of Economic Agriculture and Development. Tenth year, (37), $107-132$.

The collection of fifth five-year plan of the Islamic Republic of Iran. (2010). Retrieved from http:// www.amar.org.ir

\section{Copyrights}

Copyright for this article is retained by the author(s), with first publication rights granted to the journal.

This is an open-access article distributed under the terms and conditions of the Creative Commons Attribution license (http://creativecommons.org/licenses/by/3.0/). 